\title{
Fast Fourier Transform (FFT) Dalam Transformasi Sinyal Frekuensi Suara Sebagai Upaya Perolehan Average Energy (AE) Musik
}

\author{
Dine Tiara Kusuma \\ Institut Teknologi PLN \\ dinetiarakusuma@gmail.com
}

\begin{abstract}
Sound Frequency is the vibration of a signal heard by humans produced by sound waves that have frequencies between $20 \mathrm{~Hz}$ to $20.000 \mathrm{~Hz}$. In the information retrieval system of a music, the music extraction process is needed to become a sound frequency signal. The purpose of this research is to find the Average Energy ( $A E)$ value which is one of the parameters used in the information retrival music. Fast Fourier Transform (FFT) is a method used to transform sound signals into frequency spectrum based sound signals that can be used in the process of analyzing sound data further. Based on the tests of the music used in this study, the Average Energy (AE) value of 0.00044998 was obtained.
\end{abstract}

Keywords: Sound Frequency, Fast Fourier Transform (FFT), Average Energy (AE), music, signal

\section{ABSTRAK}

Frekuensi Suara adalah getaran sinyal yang terdengar oleh manusia yang dihasilkan oleh gelombang bunyi yang memiliki frekuensi antara $20 \mathrm{~Hz}$ hingga $20.000 \mathrm{~Hz}$. Dalam sistem temu kembali informasi dari sebuah musik diperlukan proses ektraksi musik menjadi sinyal frekuensi suara.Tujuan dari penelitian ini adalah untuk mencari nilai Average Energy (AE) yang merupakan salah satu parameter yang digunakan dalam information music retrival. Fast Fourier Transform (FFT) adalah metode yang digunakan untuk mentransformasi sinyal suara menjadi spectrum suara berbasis sinyal frekuensi yang dapat digunakan dalam proses analisa data suara lebih lanjut. Berdasarkan ujicoba dari musik yang digunakan pada penelitian ini diperoleh nilai Average Energy (AE) sebesar 0.00044998

Kata kunci: Frekuensi Suara, Fast Fourier Transform (FFT), Average Energy (AE), musik, sinyal 


\section{PENDAHULUAN}

Musik merupakan kesatuan nada dan suara yang disusun sedemikian rupa sehingga mengandung irama. Dalam ilmu temu kembali informasi yang terdapat dalam musik banyak hal yang dapat ditemui. Salah satu nya adalah klasterisasi genre musik. Pada penelitian yang berjudul "Pendekatan Model Partitioning Around Medoids (PAM) Dalam Klasterisasi Genre Musik Berdasarkan Karakteristik Musik" dijelaskan bahwa parameter yang digunakan dalam proses cluster adalah dari nilai tempo, birama, dan Average Energy (AE). Nilai tempo dan birama dapat diperoleh dari partitur musik yang akan di cluster sedangkan nilai Average Energi (AE) dapat diperoleh dengan menggunakan metode perhitungan tertentu.

Dalam sebuah musik Average Energy (AE) merupakan faktor yang digunakan untuk mendeteksi karakter dan pola suara yang dihitung dari nilai rata-rata energy dari sebuah sinyal frekuenasi suara. Dalam mencari nilai dari Average Energy (AE) sebuah musik dibutuhkan suatu metode tertentu, karena suara yang terdapat didalam sebuah musik tidak dapat serta merta langsung menghasilkan sebuah nilai. Salah satu metode yang dapat digunakan untuk memperoleh nilai Average Energy (AE) ini adalah dengan Fast Fourier Transform (FFT). Fast Fourier Transform (FFT) adalah metode yang dapat digunakan untuk transformasi sinyal suara menjadi sinyal frekuensi. Sinyal suara yang terdapat dalam sebuah musik merupakan sebuah sinyal analog yang harus di konversi menjadi sebuah sinyal digital. Fast Fourier Transform (FFT) akan mengubah sinyal analog ini menjadi sinyal digital berupa gelombang spektrum suara berbasis frekuesi.

Sebuah musik yang sudah ditransformasikan menjadi sebuah sinyal digital akan menghasilkan nilai histogram dari musik tersebut. Nilai histogram inilah yang dapat digunakan untuk memperoleh nilai Average Energy (AE) lebih lanjut. Berdasarkan kebutuhan perolehan nilai Average Energy (AE) dalam sistem temu kembali informasi dari sebuah musik maka pada penelitian ini akan membahas bagaimana Fourier Transform (FFT) dapat membantu mentransformasikan sinyal suara digital menjadi nilai histogram yang dapat membantu menghasilkan nilai Average Energy (AE).

\section{METODE/PERANCANGAN PENELITIAN}

\subsection{Fast Fourier Transform (FFT)}

Fast Fourier Transform (FFT) adalah teknik perhitungan operasi matematika yang digunakan untuk mentrasformasi sinyal analog menjadi sinyal digital berbasis frekuensi. Fast Fourier Transform (FFT) membagi sebuah sinyal menjadi frekuensi yang berbeda-beda dalam fungsi eksponensial yang kompleks. Fast Fourier Transform (FFT) adalah algoritma untuk menghitung transformasi fourier diskrit dengan cepat dan efisien. Karena sinyal-sinyal dalam sistem komunikasi bersifat kontinyu, sehingga hasilnya dapat digunakan untuk transformasi fourier. Fourier Transform dapat didefinisikan dengan rumus:

$$
S(f)=\int_{-\infty}^{\infty} s(t) e^{-j 2 \pi f t} d t
$$

$$
\begin{array}{ll}
S(f) & =\text { sinyal dalam domain frekuensi (frequency domain) } \\
s(t) & =\text { sinyal dalam domain waktu (time domain) } \\
s(t) e^{-j 2 \pi f t} & =\text { konstanta nilai sebuah sinyal } \\
f & =\text { frekuensi } \\
t & =\text { waktu }
\end{array}
$$


Dari persamaan integral di atas dapat dilihat bahwa Fast Fourier Transform (FFT) dapat digunakan untuk menghitung nilai frekuensi, amplitudo dan fase dari suatu gelombang sinyal. Sementara untuk menghitung spektrum frekuensi sinyal pada komputer digital membutuhkan algoritma Discrete Fourier Transform (DFT). Discrete Fourier Transform (DFT) mengubah sinyal domain waktu menjadi sinyal domain frekuensi. Berikut adalah rumus dari Discrete Fourier Transform (DFT):

$$
\begin{gathered}
F(u)=\frac{1}{N} \sum_{X=0}^{X=N-1} f(x) \exp [-2 j \pi u x / N \\
F(u)=\frac{1}{N} \sum_{X=0}^{X=N-1} f(x)\left(\cos \left(\frac{2 \pi u x}{N}\right)-j \sin \left(\frac{2 \pi u x}{N}\right)\right)
\end{gathered}
$$

$\mathrm{N} \quad=$ jumlah sampel yang diambil

\subsection{Sinyal Suara}

Sinyal Frekuensi Suara adalah getaran sinyal yang terdengar oleh manusia yang dihasilkan oleh gelombang bunyi yang memiliki frekuensi antara $20 \mathrm{~Hz}$ hingga $20.000 \mathrm{~Hz}$. Berdasarkan bentuknya data dari sinyal suara dapat dibedakan kedalam sinyal analog dan sinyal digital. Sinyal dikatakan analog apabila amplitudo dari data atau sinyal tersebut terus menerus ada dalam rentang waktu tertentu (kontinyu) dan memiliki variasi nilai amplitudo tak terbatas. Sedangkan sinyal dikatakan digital apabila amplitudo dari data atau sinyal tersebut tidak kontinyu dan memiliki variasi nilai amplitudo yang terbatas.

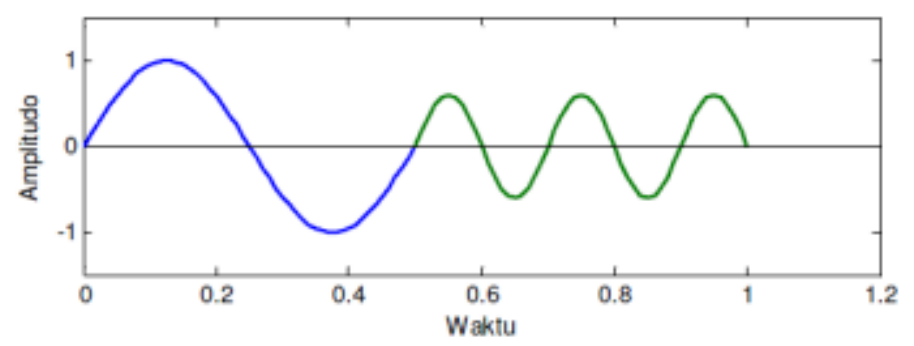

Gambar 1. Sinyal Analog

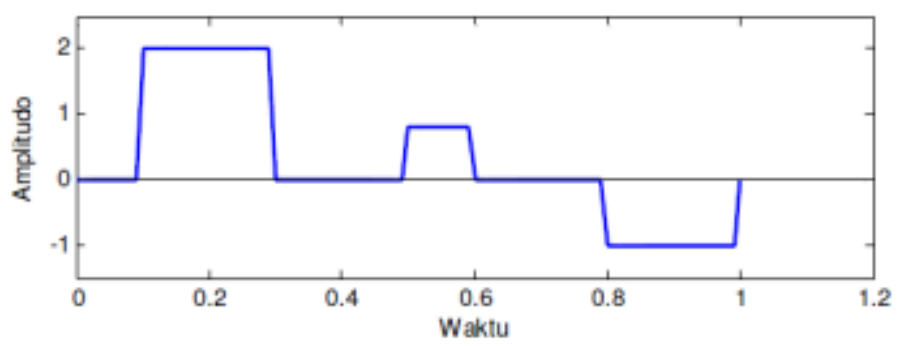

Gambar 2. Sinyal Digital

\subsection{Average Energy (AE)}

Average Energy (AE) adalah nilai rata-rata energy dari sebuah sinyal frekuenasi suara. Sebuah sinyal terdiri dari sinusoid contohnya sinyal listrik yang memiliki energi yang tak terbatas, tetapi ratarata dayanya terbatas. Formula yang di gunakan untuk mencari nilai dari Average Energy (AE) adalah sebagai berikut: 
$\mathrm{AE} \quad=$ Average Energy

$\mathrm{N} \quad=$ jumlah sampel yang diambil

$\mathrm{X}(\mathrm{n}) \quad=$ Nilai dari sample

\section{HASIL DAN PEMBAHASAN}

\subsection{Ekstrak Musik ke Sinyal Digital}

Hasil dari proses transformasi suara menjadi sinyal digital dapat dilihat pada gambar berikut:

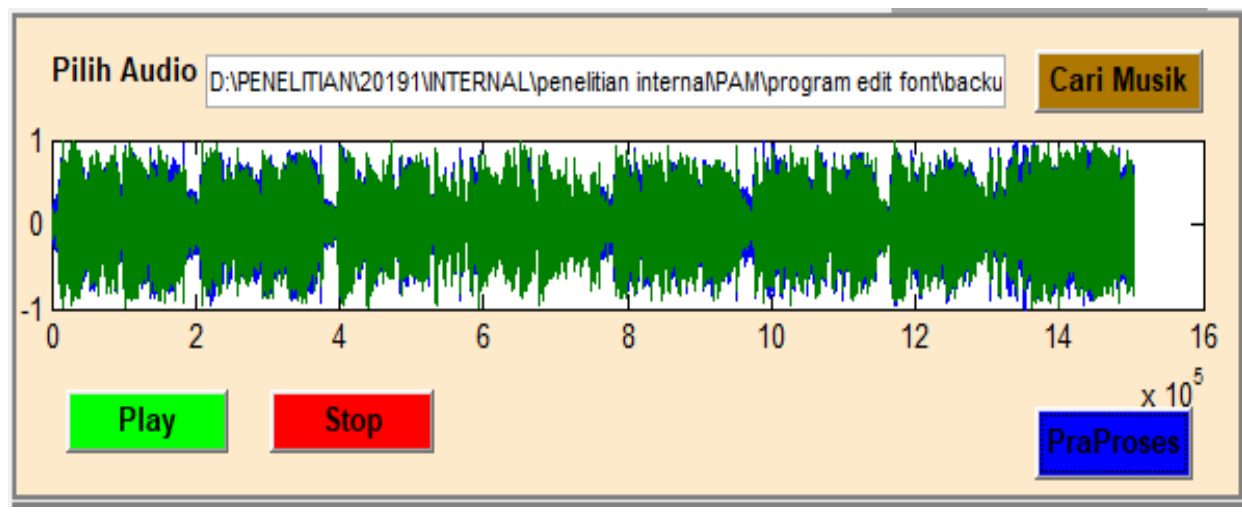

Gambar 3. Hasil sinyal digital

Gambar 3 diatas adalah tampilan untuk input data musik yang diekstraksi menjadi sinyal digital sehingga dapat diperoleh nilai-nilai yang ada di dalamnya. Pada tampilan ini dapat menampilkan sinyal spektrum musik. Ada 4 tombol pada tampilan di atas yaitu tombol Cari Musik (untuk memasukan musik ke dalam sistem), tombol play (untuk memulai mendengarkan suara dari musik), tombol stop (untuk berhenti memutar musik), dan tombol PraProses (untuk mengekstrak dan menormalkan data musik dengan Fast Fourier Transform (FFT)). Musik yang menjadi input ujicoba pada proses ektraksi di atas adalah lagu RAN - Dekat Dihati.wav dengan durasi waktu 30 detik.

\subsection{Fast Fourier Transform (FFT) Sinyal}

Setelah sinyal digital dari sebuah musik telah di temukan, maka untuk memperoleh nilai histogram dari suara musik tersebut perlu dilakukan PraProses untuk menghasilkan Fast Fourier Transform (FFT) sinyal. Berikut hasil Fast Fourier Transform (FFT) sinyal nya: 


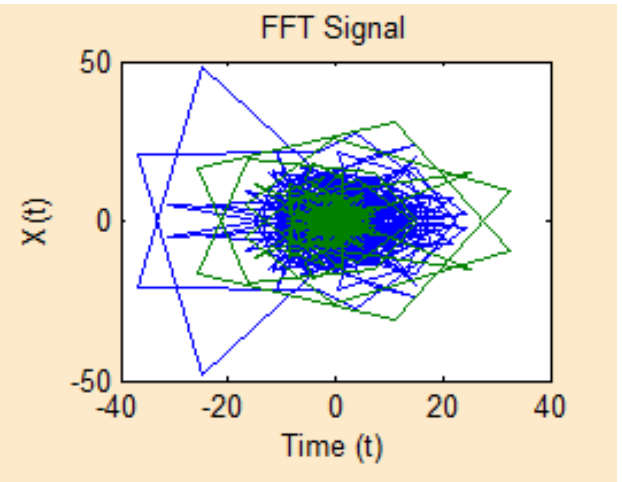

Gambar 4. FFT Sinyal

Pada gambar 4 diatas terlihat Fast Fourier Transform (FFT) sinyal dari musik yang telah dimasukan. Fast Fourier Transform (FFT) sinyal diatas terbentuk dengan tujuan untuk mencari nilai Fast Fourier Transform (FFT) histogram.

Spektrum frekuensi pada gambar 3 di atas terdiri dari 8800 sinyal input yang digunakan untuk mengitung Discreet Fourier Transform (DFT). Proses perhitungan dilakukan dengan mengimplementasikan transformasi pada 8800 sinyal input tersebut dengan rumus:

$$
F(u)=\frac{1}{N} \sum_{X=0}^{X=N-1} f(x) \exp [-2 j \pi u x / N
$$

Sehingga menghasilkan nilai Histogram:

Tabel 1. Tabel Hasil Perhitungan DFT

\begin{tabular}{|l|l|}
\hline $\boldsymbol{f ( u )}$ & \multicolumn{1}{|c|}{ Hasil dari DFT / F $(\boldsymbol{u})$} \\
\hline$f(0)$ & 0.0011 \\
\hline$f(1)$ & 0.0036 \\
\hline$f(2)$ & 0.00014 \\
\hline$f(3)$ & 0.0011 \\
\hline$f(4)$ & 0.00034 \\
\hline$f(5)$ & 0.000035 \\
\hline & $\cdot$ \\
\hline & $\cdot$ \\
\hline & $\cdot$ \\
\hline & 0.000338 \\
\hline & 0.000284 \\
\hline$f(8798)$ & 0.0016 \\
\hline$f(8799)$ &
\end{tabular}

Setelah di peroleh sinyal dengan domain frekuensi tersebut diatas maka untuk mencari Nilai Fast Fourier Transform (FFT) histogram dari sinyal di atas di Matlab menggunakan perintah: 


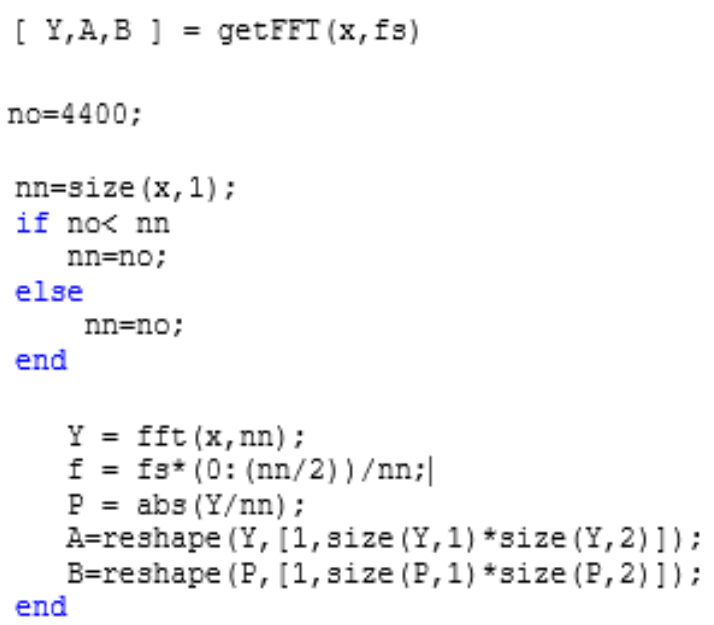

Sehingga menghasilkan Fast Fourier Transform (FFT) histogram sebagai berikut yang selanjutnya dapat digunakan untuk menghitung nilai Average Energi (AE).

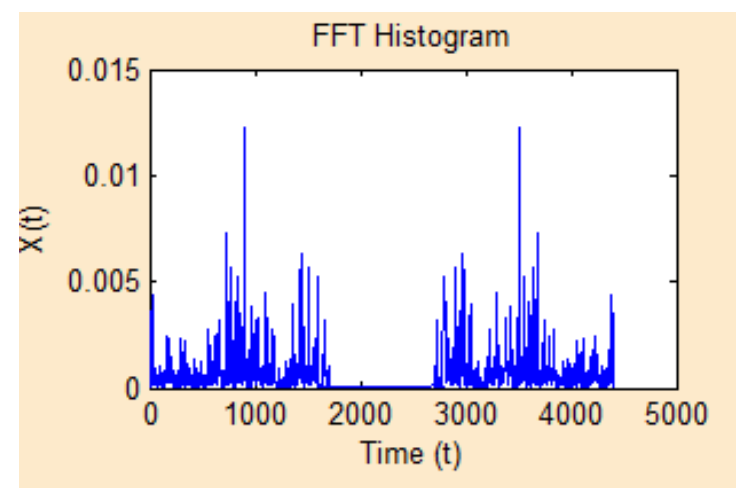

Gambar 5. FFT Histogram

\subsection{Menghitung Average Energy (AE)}

Setelah diperoleh Fast Fourier Transform (FFT) nya maka untuk mengitung Average Energy (AE) menggunakan persamaan:

$$
A E=\frac{\sum_{N=O}^{N-1} X(n)^{2}}{N}
$$

Dimana nilai frekuensi setiap sinyal dijumlahkan untuk kemudian dibagi dengan jumlah frekuensi yang tersedia.

Tabel 2. Tabel Nilai Histogram

\begin{tabular}{|c|l|}
\hline Frekuensi ke - & \multicolumn{1}{|c|}{ Nilai Histogram } \\
\hline 1 & 0.0011 \\
\hline 2 & 0.0036 \\
\hline 3 & 0.00014 \\
\hline 4 & 0.0011 \\
\hline 5 & 0.00034 \\
\hline 6 & 0.000035 \\
\hline$\cdot$ & $\cdot$ \\
\hline &. \\
\hline
\end{tabular}




\begin{tabular}{|c|l|}
\hline$\cdot$ & $\cdot$ \\
\hline 8796 & 0.000573 \\
\hline 8797 & 0.000306 \\
\hline 8798 & 0.000338 \\
\hline 8799 & 0.000284 \\
\hline 8800 & 0.0016 \\
\hline Jumlah & $\mathbf{3 . 9 5 9 8 2 4}$ \\
\hline Rata-rata & $\mathbf{0 . 0 0 0 4 4 9 9 8}$ \\
\hline
\end{tabular}

Jumlah seluruh frekuensi yang tersedia tersebut adalah jumlah frekuensi yang ada pada 1 lagu yaitu lagu RAN - Dekat Dihati menggunakan format .wav dengan durasi lagu maksimal 30 detik. Hasil nilai Average Energy ini lah yang selanjutnya akan dipergunakan untuk proses clustering pada penelitian "Pendekatan Model Partitioning Around Medoids (PAM) Dalam Klasterisasi Genre Musik Berdasarkan Karakteristik Musik" yang membutuhkan Tempo, Birama dan nilai Average Energy $(A E)$ dari sebuah lagu.

\section{KESIMPULAN DAN SARAN}

\subsection{Kesimpulan}

Berdasarkan hasil dari analisis diatas maka diperoleh kesimpulan yaitu:

1. Dalam sistem temu kembali informasi dari sebuah musik Fast Fourier Transform (FFT) dapat digunakan sebagai salah satu metode yang dapat mendukung diperolehnya nilai Average Energy (AE).

2. Musik yang digunakan sebagai data uji pada penelitian ini menggunakan lagu $R A N-$ Dekat Dihati.wav dengan durasi waktu 30 detik, menghasilkan 8800 sinyal frekuensi dengan perolehan Average Energy (AE) yaitu 0.00044998

\subsection{Saran}

Berdasarkan penelitian yang dilakukan untuk memperoleh nilai Average Energy (AE) pada penelitian ini masih menggunakan musik dengan format .wav dengan durasi tidak lebih dari 30 detik. Diharapkan pada penelitian selanjutnya format musik dapat fleksibel menggunakan format lainnya seperti .mp3 dan lain sebagainya untuk jenis musik, serta durasi waktu musik bisa lebih dari 30 detik sehingga saat proses ektraksi nilai di metode Fast Fourier Transform (FFT) dapat mempertimbangkan waktu yang berbeda dari setiap musik yang ada.

\section{UCAPAN TERIMAKASIH}

Pada kesempatan ini ucapan terimakasih yang sebesar-besarnya disampaikan kepada Institut Teknologi PLN atas segala bentuk dukungan nya agar penelitian ini dapat berjalan dengan sebaikbaiknya.

\section{DAFTAR PUSTAKA}

[1] M. Muchtar, R. Sirait, R. Rahmat, "Penerapan Perintah Suara Berbahasa Indonesia untuk Mengoperasikan Perintah Dasar di Windows", 2018

[2] R. Y. Sipasulta, A. S. M. Lumenta, S. Sompie, "Simulasi Sistem Pengacak Sinyal Dengan Metode FFT (Fast Fourier Transform)", E-journal Teknik Elektro dan Komputer (2014), ISSN 2301-8402 
[3] W. Kurniawan, "Identifikasi Speech Recognition Manusia dengan Menggunakan Average Energy dan Silent Ratio Sebagai Feature Extraction Suara pada Komputer, Biospecies Vol. 9 No.1, Januari 2016, hal. 1-6

[4] H. Sujadi, I. Sopiadi. A. Mutaqin, Sistem Pengolahan Suara Menggunakan Algoritma FFT (FAST FOURIER TRANSFORM), Prosiding SINTAK 2017, ISBN: 978-602-8557-20-7

[5] A. Syaifuddin, Suryono, "FAST FOURIER TRANSFORM (FFT) UNTUK ANALISIS SINYAL SUARA DOPPLER ULTRASONIK”, Youngster Physics Journal, Vol. 3, No. 3, Juli 2014, pp. 181-188

[6] R. Alfina, I. Arifianto, D. Astharini, P. Wulandari, Mendisain GUI Untuk Menampilkan Nilai FFT dan IFFT Menggunakan LabVIEW, in TESLA Vol. 21 No 12019

[7] S. Riyanto, A. Purwanto, Supriadi, Algoritma Fast Fourier Transform (Fft) Decimation In Time (DIT) Dengan Resolusi 1/10 Hertz, in Prosiding Seminar Nasional Penelitian, Pendidikan, dan Penerapan MIPA, pp 223-231

[8] A. Riyani, A. Nurrochman. E. Sanjaya, P. Rizqiyah, A. Junaidi, "Mengidentifikasi Sinyal Suara Manusia Menggunakan Metode Fast Fourier Transform (FFT) Berbasis Matlab", in J. Of INISITA Vol 1 No 2, pp 042-050 2019, DOI: 10.20895/INISTA.V1I2

[9] A. S. Irtawati, M. Ulfah, S. F. Rukhyah, Implementasi Metode Fast Fourier Transform (FFT) Dalam Mengklasifikasikan Suara Pria dan Wanita, in Jurnal Teknologi Terpadu Vol 7 No 2, 2019

[10] P. N. Hanggasarsari, H. Fitriawan, Y. Yuniati, Simulasi Sistem Pengacakan Sinyal Suara Secara Realtime Berbasis Fast Fourier Transform (FFT), in ELECTRICAL Jurnal Rekayasa dan Teknologi Elektro Vol 6 No 3, 2012, pp 192-198

[11] H.P. Vendira, F.Y Rumahlewang, Y. A. Lesnussa, Aplikasi Transformasi Fourier untuk Menentukan Periode Curah Hujan (Studi Kasus: Periode Curah Hujan di Kabupaten Seram Bagian Barat, Provinsi Maluku), in Jurnal Matematika Integratif Vol 10 No 2, Oktober 2014, pp 85-94

[12] F. N. Abdillah, "Implementasi Algoritma Fast Fourier Transform (FFT) dan Algoritma Harmonic Product Spectrum (Hps) pada Tuner Gitar Berbasis Android", in JURNAL NUANSA INFORMATIKA VOL 11. NO. 2, pp. 18-25

[13] M. J. Roberts, "Signals and Systems Analysis Using Transform Methods and MATLAB", Department of Electrical and Computer Engineering University of Tennessee, New York, Americas, 2012

[14] B. Alhamda, M. Adhi, D. Priambodo, H. Azhar, A. Junaidi, "Simulasi Penghilangan Noise Pada Sinyal Suara Menggunakan Metode Fast Fourier Transform (FFT)", in Journal of Informatics, Information System, Software Engineering and Applications (INISTA), pp. 2025

[15] Mursyidah, Jamilah, Zayya, "Pengenalan Karakter Suara Laki-Laki Aceh Menggunakan Metode FFT (Fast Fourier Transform)", in Jurnal Infomedia Vol.2 No.1 April 2017, pp. 2125 . 